\title{
Exploring the Relationship Between Learning and Leadership
}

\author{
Lillas M. Brown \\ Director \\ Business and Leadership Programs \\ Extension Division \\ University of Saskatchewan \\ Saskatoon, Saskatchewan S7N 5C8 CANADA \\ Lillas.Brown@usask.ca \\ and \\ Barry Z. Posner \\ Dean and Professor of Leadership \\ Leavey School of Business \\ Santa Clara University \\ Santa Clara, CA 95053 USA \\ bposner@scu.edu \\ 408-554-4634 (FAX: 408-554-4553)
}

Published

The Leadership \& Organizational Development Journal

November 2001 


\section{Exploring the Relationship Between \\ Learning and Leadership}

\section{$\underline{\text { Abstract }}$}

This paper investigates how two important research streams, namely learning and leadership, might be related with one another. Responses on the Learning Tactics Inventory (Dalton, et.al., 1999) and Leadership Practices Inventory (Kouzes and Posner, 1997) are compared for a managerial sample $(\mathrm{N}=312)$. Results indicate that more active and versatile learners subsequently consider themselves more frequently involved and engaged in leadership behaviors. Implications for transformational learning and leadership theories are explored, as well as thoughts about how the development of leadership competencies may be enhanced and affected by various learning techniques.

\section{$\underline{\text { Key Words }}$}

Learning

Leadership

Leadership Development

Learning Tactics Inventory

Leadership Practices Inventory

Transformational Learning 


\section{Exploring the Relationship Between \\ Learning and Leadership}

Learning and leadership represent two rich lines of research: One is about how people learn and the other is about how people lead. In this study we attempt to connect these two ideas together: What relationship does the way that people learn have with the manner in which they lead?

How do people learn? This has been, and continues to be, the subject of voluminous research studies. Most consider learning from either a trait-based approach or as various information-processing strategies. Similarly, researchers investigate whether learning begins from an "inside out" or "outside in" perspective. In the last two decades, scholars have advanced a "transformational learning theory" that has received more attention than any other adult learning theory and continues to be of interest (Taylor, 1997). Transformational learning theory builds upon previous lines of inquiry into adult learning such as androgogy and selfdirected learning. Mezirow (1994: 222) defines transformational learning as "the process of construing and appropriating a new or revised interpretation of meaning of one's experience as a guide to action.” Essentially this approach to learning is about change - dramatic and fundamental change in the way we see ourselves and the world in which we live. Kegan (2000) describes transformational learning as an expansion of consciousness and observes that this kind of learning is more than merely adding to what we already know. "Transformational learning shapes people,” asserts Clark (1993:47): "they are different afterwards, in ways both they and others can recognize.”

Rather than focusing on adult learner characteristics, as andragogy and self-directed learning theories tend to do, transformational learning centers squarely on the cognitive process of learning. The mental constructions of experience, inner meaning, and reflection are common components of this approach (Merrion \& Cafferella, 1999). Key concepts in transformational learning are: (a) experience - critical incidents or trigger events; (b) critical reflection - content reflection, process reflection, and premise reflection (examine long held beliefs, values about the experience); (c) affective learning - feelings play a primary role in triggering reflection, (d) dialogue and relationships that are supportive and trusting and, (e) individual development (Taylor, 2000). Experience is envisioned as the starting point in this approach and becomes the content for reflection. Engaging the life experience in a critically reflective manner is a necessary condition for transformation. Indeed, the entire process of learning is a journey of change - change that is growth enhancing and developmental (Mezirow, 2000).

The question of how people learn to lead is more narrowly focused than the broader topic of learning and, not surprisingly, reveals more widespread consensuses. For instance, in analyzing thousands of case studies, Kouzes and Posner (1995) found that people reported learning how to lead from three sources: trial and error, observation of others, and education. Honeywell undertook a six-year research program to determine how managers learn to manage. Findings from their study revealed these three categories: job experiences and assignments, relationships, and formal education/training (Zemke, 1985). The Center for Creative Leadership 
interviewed successful executives to find out what career events they considered to be important in their development and clustered the results into these sets: job assignments that the executives had experienced; other people with whom they had come into contact; hardships they had endured; and formal training (McCall, Lombardo, \& Morrison, 1988). More recently, research from the Center indicates that about $75 \%$ of the events that individuals report as critical to their careers comes from a combination of learning from the work itself and learning from others (Dalton, Swigert, VanVelsor, Bunker, \& Wachholz, 1999).

The case has been made about the importance of learning as a foundational element in effective leadership. Vaill (1999), for example, explains how the importance of learning is underscored by the exceedingly turbulent and unpredictable organizational environments within which corporate managers and executives are working. There is basically no limit, he says, to the kinds of learning a contemporary leader may have to engage: "All managerial leaders are feeling a dramatic quickening in the pace of change, an increasing complexity to their choices and a greater and greater cost of being wrong. There is a continual stream of things managers have to learn in order to thrive in this environment” (119). It may make more sense to say that in the present world, leadership is not learned but rather that it is learning. When we observe a leader at work, what we may really be observing is a learning process - and an exceedingly complex learning process at that.

How do people lead? This question is also the object of voluminous study, and reviews of this extensive literature can be found elsewhere (e.g., Bass, 1990; Conger, 1999, Yukl, 1994). Current behavioral approaches to leadership, however, are more consistent than inconsistent, and vary more in their emphasis and semantics. Bennis and Nanus (1997), for example, describe the four keys of effective leadership as: Attention through vision, meaning through communication, trust through positioning, and the deployment of self through positive self-regard. Bass (1994) has described transformational leadership along the dimensions of charismatic leadership, inspirational leadership, intellectual stimulation, and, individualized considerations. The five key practices of leaders, according to Kouzes and Posner's (1995) framework of what people are doing when they are leading, include: Challenging the process, inspiring a shared vision, enabling others to act, modeling the way, and encouraging the heart. Moreover, it's been claimed that "effective leaders are constantly learning. They see all experiences as learning experiences.” (Kouzes \& Posner, 1995:323).

Bennis and Nanus (1997) describe transformational leadership as achieving significant changes that reflects the community of interest of both leaders and their constituents, freeing up and pooling collective energies in pursuit of a common vision. They go on to make the following four generalizations about transformational leadership: 
1. It is a collective, there is a symbiotic relationship between leaders and followers, and what makes it collective is the subtle interplay between the follower's needs and wants and the leader's capacity to understand, one way or another, these collective aspirations.

2. Leadership is causative, meaning that leadership can invent and create institutions that can empower employees to satisfy their needs.

3. Leadership is morally purposeful and elevating, which means, if nothing else, that leaders can, through deploying their talents, choose purposes and visions that are based on the key values of the workforce and create the social infrastructure that supports them.

4. Leaders can move constituents to heightened degrees of consciousness, such as liberty, justice, and self-actualization.

What this indicates is that leadership is closely connected with the concept of change, and change, in turn, as we have already indicated, is at the essence of the learning process. The wellspring of learning organizations is transformational leaders (Rolls, 1995). Indeed, it is precisely because leaders have successfully navigated deep personal change that they are able to create conditions in which employees can themselves be engaged in the practices of learning organizations.

This interest in connecting learning (and dealing with change) and actually providing leadership is relevant to the growing interest in the development of leaders. Today's turbulent economic marketplace requires people who thrive on the challenge of change, who can foster environments of innovation, who encourage trust and collaboration, and who are prepared to chart a course into uncharted territories. The Conference Boards of the United States and Canada have both recently affirmed that leadership is the number one competency that organizations seek to develop in their people (Hackett, 1997; McIntyre, 1997). Learning how to lead is both a personal and organizational imperative.

McCall 1024 et al. (1988) point out that learning by managers is essential to their job performance and career success (and presumably, organizational effectiveness). As managers improve their ability to learn from experiences in the workplace (e.g., through challenging assignments, role models, hardships and the like) the better or more effective they will be as leaders. Lombardo, Bunker and Webb (1990) argue that people who use a variety of learning tactics will be best able to learn from their experiences and will consequently be more effective in the workplace.

A series of empirical studies from the Center for Creative Leadership has explored this relationship between learning and leadership (Dalton et al., 1999). With a sample of army captains ( $\mathrm{N}=279$ ) a modest relationship was found between learning tactics and self-reported effectiveness along these seven dimensions: Acts with integrity, seeks broad business knowledge, brings out the best in people, adapts to cultural differences, insightfulness, commitment to making a difference, and has the courage to take risks. However, in a follow-up study involving a small civilian sample $(\mathrm{N}=36)$, no significant relationships were found between participants' learning tactics and the ratings of their effectiveness by their supervisors. Potential managerial effectiveness was related to learning in a study involving individuals from a cross-section of organizations $(\mathrm{N}=188)$. In this study learning tactics were related to such 
abilities as turning around an organizational unit, starting something from scratch, having a significant role in an acquisition, negotiating a major contract, being promoted two or more levels, and the like. Most of these dimensions of effectiveness might be better thought of as essential aspects of managerial or leadership behavior that result in being effective.

In this study we were interested in extending the research on the relationship between learning and leadership. The guiding hypothesis was that individuals who are better learners are more engaged in leadership behaviors.

\section{SAMPLE AND METHODOLOGY}

Respondents for this study were drawn from three sources. The first were mid-level managers from a large high-technology company enrolled in a university-based management development course. The second were working professionals, across a variety of hightechnology organizations, engaged in an evening MBA program. The third were a cross-section of managers enrolled in an Executive MBA program. The total sample consisted of 312 respondents. The demographic characteristics of the corporate managers and managers from the Executive MBA program were very consistent; the evening MBA participants were younger but all had both managerial and work experiences within similar corporate environments. There were 114 women (36\%) in the sample. Post-hoc analysis revealed no statistically significant differences on any of the instruments or findings based upon respondent gender.

Respondents completed both the Learning Tactics Inventory (LTI) and the Leadership Practices Inventory (LPI). The LTI is a 32-item set of statements intended to assess how people report learning when faced with "the challenge of an unfamiliar task or experience." Each statement is measured on a five-point Likert scale, with 1 anchoring "I have almost never used this approach" to 5 indicating "I have almost always used this approach." The LTI yields four scales, each of which represents a different tactic for learning:

- $\quad$ Action (e.g., Am proactive in my approach, preferring to learn by trial and error);

- $\quad$ Thinking (e.g., Read articles or books or go online to gain knowledge and background);

- $\quad$ Feeling (e.g., Confront myself on what I am worrying about); and,

- $\quad$ Accessing Others (e.g., Bounce my hopes and fears off someone I trust).

Each of the learning tactics (scales) is measured by eight statements and Cronbach's alpha (internal reliability) for each has been reported at .70 or greater. In this study, Cronbach's alpha scores were slightly lower (ranging between .62 and .72). A variety index is computed by adding up how many tactics the respondent reports using where the respondent's score was above the median for the sample. Scores can range from zero to four; thus a score of four (4) means the respondent scored above the median on all four learning tactics and is a highly versatile learner. More information about the LTI is available in Dalton, et al. (1999).

The Leadership Practices Inventory reports on the frequency with which respondents engage in a specific set of leadership behaviors. Each of the 30 items on the LPI is assessed 
using a ten-point Likert scale, with 1 indicating "I almost never engage in this behavior" to 10 indicating that "I almost always engage in this behavior." The LPI yields five scales, each of which represents a separate set of leadership behaviors:

- $\quad$ Challenging the Process (e.g., I seek out challenging opportunities that test my skills and abilities);

- $\quad$ Inspiring a Shared Vision (e.g., I describe a compelling image of what our future could be like);

- $\quad$ Enabling Others to Act (e.g., I develop cooperative relationships among the people I work with);

- $\quad$ Modeling the Way (e.g., I set a personal example of what I expect from others); and,

- $\quad$ Encouraging the Heart (e.g., I praise people for a job well done).

Each of these five leadership practices (scales) is measured by six statements and Cronbach's alphas for each have been reported at .70 or greater. In this study, Cronbach's alpha scores were roughly equivalent (ranging between .66 to .84). A composite score is not typically computed for the LPI; however, in this study a composite score was calculated following the same procedure for constructing the variety index on the LTI. Hence a transformational leadership index was computed by adding up how many leadership practices the respondent reported using where the respondent's score was above the median for the sample. Scores could range from 0 to 5; thus a score of five (5) means the respondent scored above the medium on all five leadership practices and is a high transformational leader. More information about the LPI is available in Kouzes and Posner (1997).

We hypothesized, in general, that the various learning tactics and leadership practices would be positively correlated. Better learners, as defined by the Learning Tactics Inventory, are those with higher scores. More effective leaders, as defined by the Leadership Practices Inventory, are likewise those with higher scores. Variety, accordingly, was also hypothesized to be positively related with Transformational Leadership: People with the greatest ability to face unfamiliar and new situations with a repertoire of ways of learning would engage most frequently in behaviors associated with transformational leadership.

\section{RESULTS}

Table I presents correlations between respondents’ learning tactics and their leadership practices. Cronbach's alphas for each scale are also reported. As this data illustrates, each of the learning tactics, as hypothesized, was significantly correlated with each of the leadership practices. The strongest correlations with leadership were with the learning tactic of Thinking and the weakest correlations were with Accessing Others. Variety and Transformational Leadership were also significantly correlated. 
Table II affords a more detailed view of the previous findings by looking at the relationship between respondents' frequent (high or above the median) or less frequent (low or below the median) use of each of the four learning tactics and how this manifested itself in their use of each of the five leadership practices. This analysis gives strong support to the argument that learning is subsequently related to leadership. Better learners, those with higher scores, regardless of learning mode, consistently engaged in leadership practices more frequently than did those in the low learning category. For example, those most comfortable with using the Action learning tactic reported more frequently engaged in Challenging the Process. This same pattern was repeated for the other three learning tactics and Challenging. This same pattern was also found for Inspiring, with the better learners across all four tactics more frequently engaged in this leadership practice.

High Action learners were generally engaged more frequently in four of the five leadership practices (challenging, inspiring, enabling, and modeling) than those in the low Action learning mode. High Thinking learners were more frequently engaged in all five of the leadership practices than their counterparts in the low Thinking learners' category. High Feeling learners engaged in the leadership practices of Challenging, Inspiring, Modeling and Encouraging more frequently than those in the low Feeling group. Accessing Others as a mode of learning differentiated between high and low learners on three leadership dimensions: Challenging, Inspiring and Encouraging.

\section{DISCUSSION}

Managers differed in the extent to which they used various learning strategies when confronted with an unfamiliar task or experience. They also differed in the extent to which they engaged in a set of important leadership behaviors. Systematic relationships were found between these two experiences, such that a positive relationship was found between how people learned and how they acted as leaders. Respondents who reported using more frequently any one of the four learning tactics (action, thinking, feeling, and accessing others) also reported engaging more frequently in leadership behaviors like challenging, inspiring, enabling, modeling, and encouraging. Composite learning and leadership indices (variety and transformational leadership) were significantly correlated $(r=.33, p<.001)$.

It might be argued that leaders from highly technical companies, such as those involved in this study, who are highly educated in a traditional sense, would have well-developed "thinking” learning tactics, and that they would be more self-reliant, independent and not particularly keen to "access other people” for help. In a challenging (new) environment, they may rely on what is known and what is comfortable as a way of learning. This cognitive preference, however, is likely to be quite limiting into the future. The techno-hip readers of FAST COMPANY magazine give credence to this view when they reported social skills as more important to future business success than internet skills (1999). This suggests that learning tactics, such as "feeling” and "accessing others" would best assist in developing these leadership abilities.

Consider the description Argyris (1991) provides of typical well-educated highlycommitted professionals who occupy senior executive positions, who are almost always successful at what they do, and who rarely experience failure. As a result, it might be argued 
that they never learn how to learn from failure, never develop the tolerance for feelings of failure or the skills to deal with these feelings, and ultimately develop even some fear of failure. They typically screen out criticism, become defensive, and put the blame on external factors and others, all which blocks learning. Again “accessing others” and (acknowledging) "feelings” are tactics that break down defenses which, in turn, block learning.

Transformational learning concepts provide insights for leveraging the effective development of leadership competencies. Taylor (2000) describes the conditions conducive to fostering transformational learning as:

(a) creating a climate of openness, safety and trust, being learner centered and encouraging self-directed learning;

(b) providing learning activities that encourage the exploration of alternative personal perspectives via questioning, critical self reflection and self dialogue;

(c) facilitators who are trusting, empathetic, caring, authentic, with integrity, able to bring forth feelings to promote critical reflection;

(d) providing opportunities for assessment and feedback; and,

(e) allowing and/or providing the time necessary for the personal exploration and the intensity of the experience.

These conditions underscore the evidence supporting comprehensive, longer-term leadership development programs with retreats and coaching as offering the best opportunities for leadership development. Patricia Cranton endorses professionaldevelopment as transformative learning and supports practical and personal approaches that are self directed, reflective and transformative (1996).

Closely related to transformational learning theory are the principles of adult learning. A key implication from these findings is the importance of following adult learning principles in designing and delivering leadership development programs (Zemke \& Zemke, 1995). Using a tool like the Learning Tactics Inventory helps leaders become more self aware of their preferred learning tactics, and more importantly the tactics to develop and use to be a more versatile learner.

A trademark competency of future leaders will be their ability to instill a learning mindset into their organizations (Conger \& Benjamin, 1999). The upcoming generation of leaders will have to be a generation of learning evangelists. By accentuating the importance of learning and establishing a context where employees want to and are able to learn, leaders will be more capable of strengthening their organizations for future challenges and increasing competitive and innovative abilities. The effective development of future leaders will require leveraging adult learning principles as well as creating the conditions that foster transformational learning if such programs hope to accelerate and enhance strategic thinking and other equally critical and complex capabilities. The challenge, as suggested by the findings of this study, requires being able to translate learning principles into a meaningful leadership development experience that facilitates and, in fact, accelerates the learning process. 
Before concluding, we should point out some of the limitations to this study. All of the data is self-reported and the sample fairly homogenous in organizational backgrounds, and although the relationships are consistent across individuals they may be the simple result of selfreport biases. Measures of learning tactics and more independent or third- party reports of leadership behaviors would help to substantiate these relationships. These quantitative findings would certainly be enriched through various qualitative methodologies, such as case studies and interviews with leaders.

Likewise, knowledge about the effectiveness of the respondents as leaders would go a long way toward increasing the validity of the relational findings. An implicit assumption in this study was that learning precedes leadership. A more complex investigation, and conceptual model, would examine how leadership, as an experience itself, affects people's subsequent learning inclinations. Insights from transformational learning theories also offer alternative approaches to understanding the development of transformational leadership development. Finally, greater concurrent validation would result from investigating these same relationships using different instruments of the same constructs. Questions about the generalizability of the sample for this study could be addressed by replicating the study across different (more heterogeneous) sample populations.

\section{CONCLUSION}

Leaders must establish direction in relation to the complex challenges and changes in their context, shape a culture that is conducive to that vision, and inspire their people, bringing forth their talents, uniqueness, and energies toward a worthy future. This calls for transformational leaders and results in a tremendous interest in leadership development. Leadership development is a learning process. Leadership development programs and approaches need to reach leaders at a personal and emotional level, triggering critical selfreflection, and providing support for meaning making including creating learning and leadership mindsets, and for experimentation. Transformational learning theory can be used to assess, strengthen, and create leadership development programs that develop transformational leaders.

This study presents a starting point in exploring the relationship between learning versatility and transformational leadership. Applying adult learning principles and creating conditions that foster transformational learning are essential in the design and delivery of leadership development efforts. It will be important to conduct more in-depth investigations of transformational learning and transformational leadership in order to bring these two bodies of literature, as well as research and practice, together.

Research over these past two decades underscores that the majority of leadership skills are learned from naturally occurring experiences in the work place. Being able to access and apply principles of adult learning and foster transformational learning would help aspiring leaders, those wanting to strengthen their leadership, and those concerned with the development of leadership, to accelerate and leverage leadership learning. Importantly, creating a culture of leadership and learning is the ultimate act of leadership development. 


\section{REFERENCES}

May-June.

Argyris, C. (1991), “Teaching smart people how to learn”, Harvard Business Review.

Bass, B.M. (1994), Improving Organizational Effectiveness through Transformational Leadership, Sage Publications, Thousand Oaks, California. New York.

Bass, B.M. (1990), Bass \& Stogdill’s Handbook of Leadership ( $3^{\text {rd }}$ Ed.), Free Press,

Bennis, W. and Nanus, B. (1997), Leaders: The Strategies for Taking Charge, Harper \& Row, New York.

Chawla.S. and Renesch, J. (1995), Learning Organizations: Developing Cultures for Tomorrow’s Workplace, Productivity Press, Portland, Washington.

Clark, M.C. (1993), “Transformational learning”, in Merriam, S.B.(Ed.), An Update on Adult Learning Theory: New Directions for Adult and Continuing Education, Jossey-Bass, San Francisco.

Conger, J.A. and Benjamin, B. (1999), Building Leaders: How Successful Companies Develop the Next Generation, Jossey-Bass, San Francisco.

Conger, J.A.(1999), Charismatic and transformational leadership in organizations: An insiders perpsective on these developing streams of research.. Leadership Quarterly, vol.10, (28068), 145-179.

Cranton, P.(1996), Professional development as transformative leaning, Jossey-Bass, San Franscisco.

Dalton, M., Swigert, S., VanVelsor, E., Bunker, K., and Wachholz, J. (1999), The Learning Tactics Inventory: Facilitator’s Guide, Jossey-Bass/Pfeiffer, San Francisco.

Hackett, B. (1997), The Value of Training in an Era of Intellectual Capital, The Conference Board of the USA, New York.

Kegan, R. (2000), dblquote What 'form' transforms? A constructive-developmental approach to transformative learning”, in Mezirow, J. (Ed.), Learning as Transformation: Critical Perspectives on a Theory in Progress, Jossey-Bass, San Francisco.

Kouzes, J.M. and Posner, B.Z. (1995), The Leadership Challenge: How to Keep Getting Extraordinary Things Done in Organizations, Jossey-Bass, San Francisco.

Kouzes, J.M., and Posner, B.Z. (1997), The Leadership Practices Inventory: Facilitator’s Guide, Jossey-Bass/Pfeiffer, San Francisco.

Lombardo, M.M., Bunker, K., and Webb, A. (1990), “Learning how to learn”, Paper presented at the Fifth Annual Conference of the Society for Industrial and Organizational Psychology. Miami, Florida. 
Merriam, S.B. and Caffarella, R.S. (1999), Learning in Adulthood: A Comprehensive Guide, Jossey-Bass, San Francisco.

McCall, M. W., Jr. Lomardo, M.M., and Morrision, A.M. (1988), The Lessons of Experience: How Successful Executives Develop on the Job, Lexington Books, Lexington, Massachusetts.

Mezirow, J. (1994), “Understanding transformative theory”, Adult Education Quarterly, Vol 44, pp. 222-223.

Mezirow, J. \& Associates (2000), Learning as Transformation: Critical Perspectives on a Theory in Progress. San Francisco: Jossey-Bass.

McIntyre, D. (1997), Learning at the Top: Evolution of Management and Executive Development in Canada, Conference Board of Canada, Ottawa.

Rolls, J. (1995), “The transformational leader: the wellspring of the learning organization”, in Chawla, S. and Renesch, J. (Eds.), Learning Organizations: Developing Cultures for Tomorrow's Workplace, Productivity Press, Portland, Washington

Taylor, E. (1997), "Building upon the theoretical debate: a critical review of the empirical studies of Mezirow's transformative learning theory”, Adult Education Quarterly, Vol 48, pp. 32-57.

Taylor, E. (2000), "Analyzing research on transformative learning theory”, In Mezirow, J. \& Associates (2000), Learning as Transformation: Critical Perspectives on a Theory in Progress. San Francisco: Jossey-Bass.

Vaill, P. (1999), Spirited Leading and Learning: Process Wisdom for a New Age, JosseyBass, San Francisco.

“Where are we on the web?”, (1999), Fast Company, October, p. 306.

Yukl, G.A. (1994), Leadership in Organizations, Prentice-Hall: Englewood Cliffs, New Jersey.

Zemke, R. (1985), “The Honeywell studies: how managers learn to manage”, Training, Vol, pp. 46-51.

Zemke, R. and Zemke, S. (1995), “Adult learning: what do we know for sure?”, Training, Vol, pp. 


\section{TABLE I}

Correlations Between Learning Tactics

And Leadership Practices

Learning

Leadership Practices

Tactics

Challenge Inspire Enable Model Encourage Transformational

$(.84) \quad(.68) \quad(.74)$

$(.82)$

Leadership

$\begin{array}{lllllll}\text { Action (.62) } & .35^{* * *} & .28^{* * *} & .15^{* *} & .20^{* * *} & .18^{* *} & .27^{* * *} \\ \text { Thinking (.65) } & .39^{* * *} & .36^{* * *} & .31^{* * *} & .30^{* * *} & .23^{* * *} & .39^{* * *} \\ \text { Feeling (.72) } & .30^{* * *} & .29 * * * & .18^{* *} & .25^{* * *} & .25^{* * *} & .24^{* * *} \\ \text { Accessing } & & & & & & \\ \quad \text { Others (.62) } & .14^{*} & .15^{*} & .14^{*} & .13^{*} & .23^{* *} & .18^{* *} \\ \text { Variety } & .35^{* * *} & .33^{* * *} & .23^{* * *} & .24^{* * *} & .54^{* * *} & .33^{* * *} \\ ========= & & & & & & \end{array}$

Numbers in parenthesis refer to Cronbach's alpha scores for internal reliability.

$$
\begin{gathered}
* p<.02 \\
* * p<.01 \\
* * * p<.001
\end{gathered}
$$




\section{TABLE II}

Mean Scores of Low and High Groups on Learning Tactics

$$
\text { and Leadership Practices (t-tests) }
$$

Learning Leadership Practices

Tactics

$$
\text { Challenge Inspire Enable Model Encourage }
$$

$\underline{\text { Action }}$

$\begin{array}{llllll}\text { Low (153) } & 41.4 & 37.0 & 47.9 & 45.7 & 43.8 \\ \text { High (159) } & 44.9^{* * *} & 40.0^{* * *} & 49.1^{*} & 47.7^{* *} & 45.1\end{array}$

Thinking

$\begin{array}{llllll}\text { Low (148) } & 40.8 & 36.3 & 46.9 & 45.5 & 43.3 \\ \text { High (164) } & 45.2^{* * *} & 40.7^{* * *} & 49.9^{* * *} & 47.9^{* * *} & 45.5^{* *}\end{array}$

Feeling

$\begin{array}{llllll}\text { Low (135) } & 41.6 & 36.2 & 47.9 & 45.4 & 42.9 \\ \text { High (177) } & 44.4^{* * *} & 40.4^{* * *} & 48.9 & 47.8^{* * *} & 45.7^{* * *}\end{array}$

Accessing Others

$\begin{array}{llllll}\text { Low (155) } & 42.0 & 36.8 & 47.9 & 45.9 & 42.9 \\ \text { High (157) } & 44.4^{* * *} & 40.3^{* * *} & 49.0 & 47.5 & 46.0^{* * *}\end{array}$

Numbers in parenthesis refer to sample sizes, which vary as a result of median splits.

$$
\begin{gathered}
* * p<.01 \\
* * * p<.001
\end{gathered}
$$

